\title{
Can civil rights organizations deter discrimination?
}

\author{
Gabor Simonovits* Bori Simonovits ${ }^{\dagger} \quad$ Adam Vig ${ }^{\ddagger}$ Peter Hobot $\S$ \\ Renata Nemeth $\mathbb{1}$ Gabor Csomor\|
}

October 31, 2020

\begin{abstract}
To what extent can civil rights NGOs protect ethnic minorities against unequal treatment? We study this question by combining an audit experiment of 1260 local governments in Hungary with an intervention conducted in collaboration with a major Hungarian civil rights NGO. In the audit experiment we demonstrated that Roma individuals were about $15 \%$-points less likely to receive responses to information request from local governments, and the responses they received were of substantially lower quality. The intervention that reminded a random subset of local governments of their legal responsibility of equal treatment lead to a short term reduction in their discriminatory behavior, but the effects of the intervention dissipated within a month. These findings suggest that civil rights NGOs might face substantive difficulties in trying to reduce discrimination through simple information campaigns.
\end{abstract}

Word count: 2,920

\footnotetext{
*Assistant Professor, Department of Political Science, Central European University.

${ }^{\dagger}$ Senior Lecturer at Eötvös Loránd University, Budapest Faculty of Education and Psychology

${ }^{\ddagger}$ Graduate Student at Central European University

${ }^{\S}$ Graduate Student at Central European University

${ }^{\mathbb{I}}$ Associate Professor at Department of Statistics, Eötvös Loránd University

"Independent Researcher
} 


\section{Can civil rights organizations deter discrimination?}

To what extent can non-governmental organizations (NGO) enhance responsiveness and facilitate equal access to citizens? While there is a large number of NGOs whose mission is to further these goals in many countries, how successful they are is difficult to gauge. At the same time, their efforts are much needed especially in situations where governments themselves lack the capability or the motivation to enforce equal access. Beyond ethnic discrimination in the labor market, in education, and in housing, unequal access to public services and public data seems to be a serious concern in today's Hungary according to a leading civil rights NGO. Access to public information is considered to be a crucial civil right that not only enhances the effective functioning of democratic systems, but also boosts citizens' participation in public life 1

While there exists a large and growing literature on discrimination by local governments (Hemker and Rink 2017; Distelhorst and Hou 2014) little work has been done to explore ways in which such biases may be ameliorated. To our knowledge the only such effort is Butler and Crabtree (2017) who find no effect of an information treatment delivered by researchers. One crucial issue is that interventions implemented by researchers might not be taken seriously by local governments (Kalla and Porter 2019; Butler and Crabtree 2017), and governments themselves might not have sufficient incentives to intervene when they observe discriminatory behavior.

In this paper we study the responsiveness of Hungarian local governments to request for information and their possible discrimination of the Roma minority. We focus our attention on the Roma minority in Hungary, an ethnic group that faces widespread prejudice (Simonovits, Kezdi and Kardos 2018) and discrimination in Hungary (Miller et al. 2008). We report the results of an intervention we implemented in collaboration with a major Hungarian NGO that sought to inform local governments of their duties to provide to citizens equal access to information. We evaluated this intervention with an audit study (Distelhorst and Hou 2014) that was comprised of requests sent to local governments through email, in which we randomly varied the purported ethnicity of the sender as well as the nature of the request itself. We estimated discrimination towards the Roma minority by comparing responses to inquiries sent by ostensibly Roma vs.

\footnotetext{
${ }^{1}$ https://hclu.hu/en/articles/easier-access-to-public-data-due-to-our-three-successful-lawsuits
} 
non-Roma Hungarians, and tested the impact of an intervention by comparing discrimination across treated and control municipalities.

Through our audit experiment we found that ostensibly Roma individuals were discriminated against by local governments in terms of their getting a response at all, in the quality of the information in the responses, as well as in their tone. The extent of discrimination was substantively large: Roma individuals were more than $20 \%$ less likely to receive a response, and the quality of the information they received was over $30 \%$ lower based on our qualitative coding. These results are similar in magnitude to those found by (Distelhorst and Hou 2014) as well as Einstein and Glick (2017) both in terms of baseline responsiveness and discrimination, and support (Hemker and Rink 2017) in establishing more subtle forms of discrimination.

Regarding the effect of our collaborative intervention, we found that informing local governments about their duties to provide information reduced their discriminatory behavior against the Roma. Our results suggest that the reduction in discrimination was driven by the local governments' efforts to reallocate resources to respond to Roma citizens (with less effort to do so towards non-Roma citizens), but without meaningful improvements in the quality of the responses. Exploring the randomized timing of requests vis-a-vis the intervention, we find that these short term changes by and large disappeared in a month.

These findings point to the difficulty that civil rights NGOs face in fighting unequal treatment faced by minorities. While on the one hand litigation in a few key high-profile cases can change policy outcomes, cheaper and more scalable interventions, like the one reported here, are unlikely to lead to long-lasting effects.

\section{Research design}

Our study took place in Hungary, and we targeted local municipalities. While Hungary has more than 3,000 settlements that elect local governments, the smallest of them are administered by "shared" local governments. Since 2012, small settlements have been allowed to form such joint municipalities in order to cut administrative costs. Thus, our unit of analysis are partly municipalities that serve several settlements. Among other things, one purpose that these local governments serve is to provide information to their constituents as well as to anyone inquiring about local issues. In particular, the Hungarian Information Law of 2011 mandates that any 
request of information pertaining to the operation of the local government, or local issues, qualify as a request for public data, and as such local governments are mandated to disclose the requested information within 15 days.

\section{Audit experiment}

Our audit study employed a within-subjects design (Fang, Guess and Humphreys 2019) in which local governments were contacted from fake email accounts signaling the sender's Roma or non-Roma ethnicity. The emails were sent out in two waves: from July 9 to July 17, and then from August 9 to August 17. Altogether we attempted to send 2,520 different emails from 9 different accounts 2

We included one of four different requests in these emails. The first was a question about a biking trip that the requester planned near the targeted town. The second one inquired about nurseries in the area and hinted at the sender's family's thinking of moving to the settlement. The third asked about the opening hours of the local cemetery and whether it was accessible to people with disabilities. The fourth one inquired about possible venues for a wedding in the area ${ }^{3}$ We sought to balance a variety of considerations when designing these requests. First, we wanted to maximize the appropriateness of the four inquiries from the viewpoint of the targeted municipalities in order to reduce the possibility that they would find out about our research objective. Second, we sought to homogenize the length of the requests and ask specific questions so that we could evaluate the quality of the responses.

The key manipulation in our email request was the purported ethnicity of the requester, which we randomly assigned as either Roma or non-Roma. We cued Roma ethnicity using stereotypically Roma sounding names that formed the basis of the fake email addresses, and they were also included in the emails themselves. We also varied the gender of the requester through the email address and the signature. We held the style of the email constant and we used a relatively educated language in order to increase baseline response rates.

In our within subject design each municipality received two emails. The order of the gender and ethnicity was independently randomized so that each municipality received a Roma and a non-Roma request. Finally, a last treatment arm randomly assigned whether municipalities

\footnotetext{
${ }^{2}$ We had to replace one fake email address as it was shut down by Google.

${ }^{3}$ We provide the full wording of these emails in Online Appendix B2.
} 
were followed-up if a response was not received within a week. As we explain below the purpose of this treatment arm was to introduce exogenous variation into the response probability in order to mitigate non-random missingness in our measure of response quality $\left.\right|_{4} ^{4}$

\section{Intervention}

The intervention was carried out by the Hungarian Civil Liberties Union (HCLU, Hungarian: Társaság a Szabadságjogokért, abbreviated TASZ), one of the most significant Hungarian civil rights NGO. HCLU was founded in 1994, it has focused its efforts on monitoring legislation, pursuing high profile litigation, and providing free legal aid assistance. Given HCLU's interest both in the transparency of local governments and in discrimination, it seemed the most credible source for our information campaign.

The information email was designed in a collaborative effort between the research team and legal specialists of HCLU. The email first introduced HCLU and mentioned that one of the NGOs main goal was to facilitate equal access to public data. Then, it explained the legal status of requests sent to local governments (see above). It also emphasised that municipal governments were legally bound to respond to all requests. Finally, it reinforced the norm of the equal treatment of citizens requesting information. The email included the official stamp of the organization and was signed by a manager of the organization.

We used block randomization to obtain a treated sample of municipalities that the letters were sent to. In particular, we created blocks crossing county and population quintiles. The emails were sent out by HCLU on June 26, 2020, 2 weeks before the first round of the audit. With the use of mass mailing software we were able to identify local governments that opened the email 5

\section{Dependent measures and analysis}

Our primary outcome was the receipt of a response to a given request. We coded a request as having received a response if (1) it was sent within the 15 days mandated by law, and (2) was

\footnotetext{
${ }^{4}$ The audit study received IRB clearance and was compliant with relevant Hungarian law. We debriefed the research subjects soon after the data collection phase was completed (October, 2020).

${ }^{5}$ It is also important to mention that the NGO we cooperated with is an independent organization whose name and activities are perceived to be connected and associated with liberal and anti-government political views. In other words, the participation of the given NGO in our research project might also have effected our results, to an unknown extent.
} 
not an automatic reply. To obtain more subtle measures of discrimination research assistants scored responses on two dimensions. First, we defined helpfulness helpfulness as the degree to which the response provided information requested by the sender. The advantage of this measure is that we can score this measure even for requests that did not receive a response as zero 6 Second, we defined politeness as the degree to which the response was respectful. 7

We explore two main sets of quantities of interest. First, we estimate baseline levels of discrimination as the differential likelihood and quality of responses received by minority and majority senders. To measure baseline discrimination in receiving a response we estimate linear models that compare the probability of response across requests sent by Roma (minority) and non-Roma (majority) senders to the same municipality. Technically, this corresponds to linear probability models with unit fixed effects. One complication that arises here is that we only observe response quality for requests that were actually responded to. Naive comparisons of response quality conditionals on observing a response would lead to post-treatment bias Coppock et al. (2019). To mitigate this problem we utilize a Heckman selection procedure where the excluded variable in the selection equation is an indicator for municipalities that were planned to be followed up in the case of no response. Given that this indicator is randomly assigned, this procedure leads to consistent estimates even in the face of missing outcomes due to non-random selection.

Second, we explore the impact of the intervention on discrimination. To explore the effect of intervention on discrimination, we estimate the same models but include an indicator for Treatment status, Roma sender, and their interactions. For this analysis, we also assess the persistence of a possibly occurring treatment effect by comparing the effect of the intervention across the two waves as well as by estimating non-parametric models assessing decay.

Our experiment was pre-registered and we made plans of following a declared pre-analysis plan. In our main text, we deviate from our PAP in two ways. First, we report results separately for the two waves of the experiment given that we uncovered very large differences in the treatment effects in post-hoc analysis. Second, we report analysis without the covariates we declared in the PAP (type of request, the gender of the sender and block fixed effects) as thees

\footnotetext{
${ }^{6}$ The rationale for this was that we instructed our coders to give 0 - the lowest score - to responses which were equivalent to not receiving any response at all.

${ }^{7}$ Both dimensions were measured on a four point scale and were rescaled to lie between 0 and 100 . We present the descriptive statistics and details of the coding instructions as well as examples in Online Appendix B.
} 
covariates did not appear to reduce variation in the outcome. Results following the PAP are very similar to the ones reported in the main text and are included in the Online Appendix.

\section{Results}

We begin our analysis by reporting discrimination against the Roma. Specifically, we focus our attention on municipalities in the control group (i.e. those who were not sent an email by HCLU) and compare our outcome measures between requests sent by minority and majority senders. For outcome measures observed for each request we report estimates of discrimination estimated via OLS regressions with unit fixed effects, corresponding to paired t-tests. For outcomes only observed for requests receiving a response we estimate discrimination utilizing Heckman selection models.

Table 1: Baseline rates of discrimination

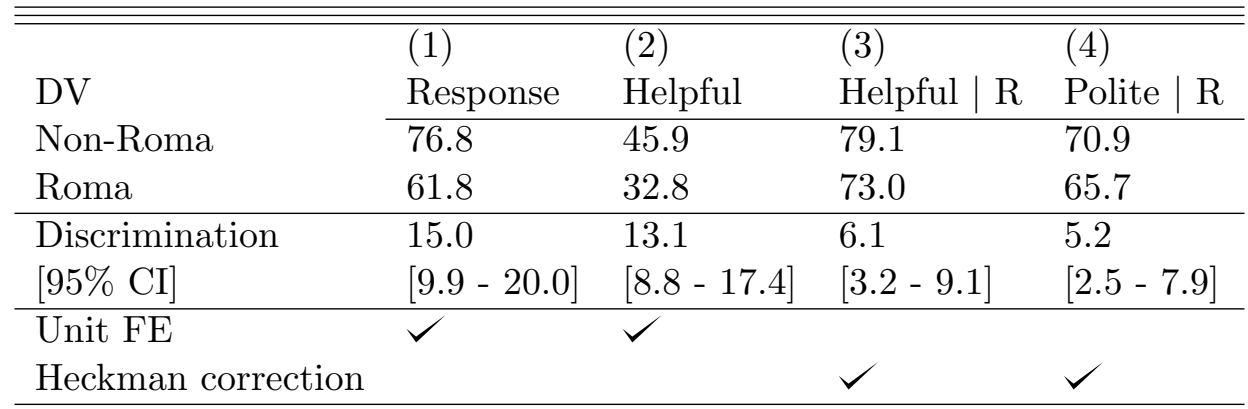

Notes: Estimates in (1) and (2) are from linear models with municipality fixed effects. Estimates in (3) and (4). are from Heckman selection models with randomly assigned follow-up as an excluded predictor of the selection equation. 95\% confidence intervals are computed based on standard errors clustered by municipality.

We report baseline rates of anti-Roma discrimination in the control group in Table 1. We find strong evidence that requests sent by individuals perceived as Roma were much less likely to receive a response compared to identical requests made by non-Roma individuals. The estimated difference is about 15\%-points, or over $20 \%$ of the baseline response rates amounting to $76 \%$ (column 1). These estimates are quite stable across three different model specifications and allow us to rule out discrimination rates below $10 \%$ at $95 \%$ significance. These findings are similar to those found by (Distelhorst and Hou 2014) as well as Einstein and Glick (2017) both in terms of baseline responsiveness and discrimination.

We find similar patterns analyzing the content of the emails. First, when we use our compre- 
hensive measure of response quality that imputes 0 for requests that did not receive a response, we find even more striking levels of discrimination: a 15 points difference, or an almost $30 \%$ difference compared to the baseline experienced by non-Roma senders (column 2). Using our sample selection models we find smaller, but still substantively important differences across the responses received by the non-Roma and the Roma. These differences in terms of information content and tone were on the magnitude of 5 points on a 100-point scale, or about $10 \%$ of the quality of emails received by non-Romas (columns 3 and 4).

Table 2: Treatment effects on response rates

\begin{tabular}{|c|c|c|c|c|c|c|c|c|}
\hline & \multicolumn{4}{|c|}{ Wave 1} & \multicolumn{4}{|c|}{ Wave 2} \\
\hline & $(1)$ & $(2)$ & $(3)$ & $(4)$ & $(5)$ & $(6)$ & $(7)$ & (8) \\
\hline & $\mathrm{R}$ & $\mathrm{H}$ & $H \mid R$ & \begin{tabular}{l|l}
$P$ & $R$
\end{tabular} & $\mathrm{R}$ & $\mathrm{H}$ & $H \mid R$ & \begin{tabular}{l|l}
$P$ & $R$
\end{tabular} \\
\hline \multirow[t]{2}{*}{ Roma } & $-12.5^{*}$ & $-12.9^{*}$ & $-8.1^{*}$ & $-5.9^{*}$ & $-18.1^{*}$ & $-14.2^{*}$ & $-5.2^{*}$ & $-4.8^{*}$ \\
\hline & {$[3.6]$} & {$[3.3]$} & {$[2.1]$} & {$[1.8]$} & {$[3.7]$} & {$[3.1]$} & {$[2.3]$} & {$[2.1]$} \\
\hline \multirow[t]{2}{*}{ Treated } & -3.0 & $-7.9^{*}$ & -1.5 & -1.2 & 0.7 & 1.6 & 0.1 & -1.0 \\
\hline & {$[3.5]$} & {$[3.5]$} & {$[2.1]$} & {$[1.9]$} & {$[3.3]$} & {$[3.2]$} & {$[2.0]$} & {$[1.9]$} \\
\hline \multirow[t]{2}{*}{ Treated X Roma } & 9.0 & $10.6^{*}$ & 2.2 & 2.7 & 1.2 & -0.7 & 0.3 & 1.6 \\
\hline & {$[5.0]$} & {$[4.7]$} & {$[3.0]$} & {$[2.6]$} & {$[5.2]$} & {$[4.4]$} & {$[3.2]$} & {$[3.0]$} \\
\hline Heckman correction & & & $\checkmark$ & $\checkmark$ & & & $\checkmark$ & $\checkmark$ \\
\hline
\end{tabular}

Table 2 reports our estimates of the causal effect of the intervention. We report estimates separately for the two waves that took place 2.5 and 7 weeks after the intervention and again for four different outcome measures. The coefficients of interest here are (1) the treatment effect on non-Roma (second row) and the interaction between the Treatment and Roma sender (third row) capturing the reduction in anti-Roma discrimination due to the intervention. We report linear regressions in the case of outcomes observed for all requests and Heckman selection models for the helpfulness and the politeness of the responses.

Our point estimates suggest that in the short run discrimination against the Roma shrank substantially in treated municipalities. In the first wave of our experiment, Roma in the control group were about $12 \%$ less likely to receive a response, while this difference was only $3.27 \%$ in the treatment group. Similar patterns are observed when we take the amount of information into account. In contrast, we do not find similar patterns when it comes to the helpfulness and the politeness of the responses: the responses Roma senders received were of lower quality in 
both treated and control municipalities. Interestingly, we find no evidence that the intervention increased the likelihood of response or their quality for non-Roma senders. If anything, it appears that response rates to requests sent by Roma requesters increased at the expense of responsiveness to non-Roma 8

The last four columns consider the long run impact of our intervention - the extent to which the treatment changed response rates or response quality about 7 weeks after the intervention. The results are clear: the effects of the intervention appear to have dissipated entirely by the second wave. We find substantively small and statistically insignificant differences across treated and control municipalities both in terms of response rates and response quality, for both Roma and non-Roma.

Figure 1: Treatment effects decay

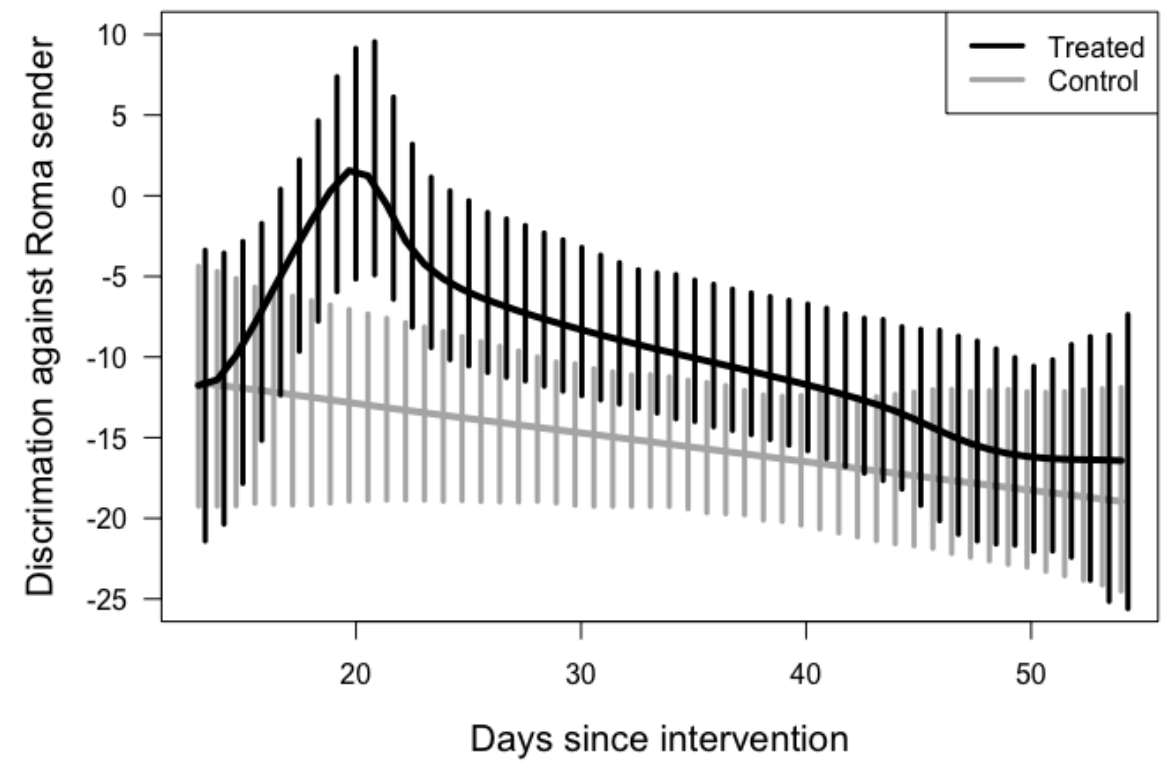

Solid dots are difference-in-differences estimates on moving-average 1 week subsamples. Error bars are $95 \%$ confidence intervals obtained through bootstrap.

To model treatment effects as a flexible function of the time lapsed since the intervention, we re-estimate treatment effects on overlapping subsamples of the dataset, with a bandwidth

\footnotetext{
${ }^{8}$ While HCLU contacted over 1,000 municipalities, only 200 (16\% of them) opened the email as recorded by the mass email system used by HCLU. As such, the weak intent-to-treat effects of the intervention are in part explained by low compliance. To estimate the treatment effect of the intervention on the treated, we estimated instrumental variables regressions with the take-up of the treatment (and its interaction with Roma senders) as an endogenous predictor and treatment assignment as instruments. Our results - reported in Online Appendix $\mathrm{X}$ - imply CACEs that are much larger in magnitude than our estimates of intent to treat effect - though also much less precisely estimated.
} 
of a week included in each subsample. We report these findings in Figure 1. It reveals that for both response rates and the information conveyed in the response discrimination against the Roma was in fact reduced for a short period after the intervention. However, this effect dissipated entirely by the second wave $9^{9}$

\section{Discussion}

This note reported the results of an intervention seeking to reduce discrimination against Roma citizens requesting information from Hungarian municipalities. To measure discrimination, we conducted an audit experiment in which we targeted Hungarian local government officials with various requests. Our intervention was an online campaign in which a major civil rights NGO reminded municipalities of their legal obligation to respond to requests for information. We found a substantively large degree of discrimination against Roma citizens both in terms of response rates and response quality. Regarding the effect of the intervention, while we found evidence that the intervention reduced discrimination in the short-run, its effects have dissipated in about a month.

What are the implication of these findings? On the one hand, our results on anti-Roma discrimination supports a growing body of evidence on how government agencies can themselves contribute to the discrimination of vulnerable minorities (Distelhorst and Hou 2014; Hemker and Rink 2017). On the other hand, our estimates of the impact of our information-campaign suggest that even interventions that are seemingly powerful in the short term can prove ineffective over the long haul. It is likely that successful campaigns aiming to reduce prejudice or discrimination against minorities will take much more effort - e.g. online or face-to-face awareness raising trainings for civil servants - and require the cooperation of targets. To the extent that such cooperation can be achieved, the design and implementation of our intervention could serve to become a promising way for NGOs and collaborative efforts with researchers to test the effects of such programs.

\footnotetext{
${ }^{9}$ In the Online Appendix, we provide additional results supporting this pattern using a semi-parametric procedure to estimate change in discrimination against the Roma through time both in the treatment and the control group. Again, we find that compared to relatively stable rates of discrimination in the control group, a sizable short term reduction occurred in the treated group.
} 


\section{References}

Butler, Daniel M and Charles Crabtree. 2017. "Moving beyond measurement: Adapting audit studies to test bias-reducing interventions." Journal of Experimental Political Science 4(1):5767.

Coppock, Alexander et al. 2019. "Avoiding post-treatment bias in audit experiments." Journal of Experimental Political Science 6(1):1-4.

Distelhorst, Greg and Yue Hou. 2014. "Ingroup bias in official behavior: A national field experiment in China." Quarterly Journal of Political Science 9(2):203-230.

Einstein, Katherine Levine and David M Glick. 2017. "Does race affect access to government services? An experiment exploring street-level bureaucrats and access to public housing." American Journal of Political Science 61(1):100-116.

Fang, Albert H, Andrew M Guess and Macartan Humphreys. 2019. "Can the government deter discrimination? Evidence from a randomized intervention in New York City." The Journal of Politics 81(1):127-141.

Hemker, Johannes and Anselm Rink. 2017. "Multiple dimensions of bureaucratic discrimination: Evidence from German welfare offices." American Journal of Political Science 61(4):786-803.

Kalla, Joshua L and Ethan Porter. 2019. "Correcting Bias in Perceptions of Public Opinion Among American Elected Officials: Results from Two Field Experiments." British Journal of Political Science pp. 1-9.

Miller, Joel, Philip Gounev, András L Pap, Dani Wagman, Anna Balogi, Tihomir Bezlov, Bori Simonovits and Lili Vargha. 2008. "Racism and police stops: adapting US and British debates to continental Europe." European journal of criminology 5(2):161-191.

Simonovits, Gábor, Gabor Kezdi and Peter Kardos. 2018. "Seeing the world through the other's eye: An online intervention reducing ethnic prejudice." American Political Science Review 112(1):186-193. 


\section{Online Appendix}

\section{A Stimuli}

\section{A.1 Letter from HCLU}

\section{Dear Sir/Madam}

The Hungarian Civil Liberties Union is a non-governmental organization defending civil rights since 1994, having concerned itself with helping Hungarian citizens to effectively exercise their civil rights - including their right to access information. HCLU sees it as its primary undertaking to defend minorities and to ensure their equal access to their rights.

In our experience, there has been an increase in requests to local governments through online channels due to the Covid epidemic. In order to support your effective and lawful operation, we would like to inform you that any requests received by local governments including those through telephone or electronic means should be understood within the framework of information freedom. According to Hungarian law, any request of information pertaining to the operation of the local government or local issues qualify as a request for public data - even if this is not explicitly stated, or the pertinent law is not specifically referred to, in the inquiry. This means that citizens have the right to be provided with a response, and that the local government receiving such a request is legally bound to respond - with the exception of cases defined by law.

The notion of "public data" is defined by the Freedom of Information Act of 2011. Accordingly, information that is known to local governments and its employees due to their job and duties - as opposed to their private data - is always public data. For instance, a phone request about how to access local healthcare services, or an email inquiring about construction permits is to be be treated as a request for public data.

- According to the law, such inquires shall be responded to within 15 days.

- A possible denial of response needs to be justified within 8 days

- If the requested information can be found online, it is sufficient to share the respective link with the requester 
- The request shall be responded to in an accessible manner of writing

- If the request is ambiguous for the local government official, instead of ignoring the request, he or she is to respond to it with a request for clarification

We view it as especially important that when approaching local governments citizens from minority groups should be treated equally. Let us work together so that everyone in Hungary may receive responses to the questions they have about local affairs, local governments, or procedures regulating the life of local citizens. In order to achieve this goal, we would like to ask you to please provide responses to citizens turning to you with requests irrespective of their identity, or mode of request.

Sincerely,

Máté Szabó Director

HCLU

\section{A.2 Attributes in audit study}

\begin{tabular}{lll}
\hline \hline Attributes & Levels & Operationalization \\
\hline HCLU Treatment & Yes, No & email \\
Randomized follow-up & Yes, No & follow-up email in 1w \\
\hline Request & nursery, hiking, wedding, cemetery & text of email, subject of email \\
Ethnicity & Roma, non-Roma & name, email address \\
Gender & Male, Female & name, email address \\
\hline \hline
\end{tabular}

\section{A.3 Request emails}

\section{A.3.1 Request 1}

Dear Sir/Madam

We are planning to visit the remains of a relative of ours who is buried in the cemetery of [TOWN]]. At this point, we are uncertain about the date of our visit, but we are planning to arrive in the evening hours, and so I would like to ask how long the cemetery is open until?

The other thing we would like to ask is whether one can drive into the cemetery by car if we have a special pass for disabled people? My mother is old and unfortunately she has difficulties walking. This would make it much easier for her to get around. 
Thank you in advance,

Sincerely

[Sender]

\section{A.3.2 Request 2}

\section{Dear Sir/Madam}

We are looking for a place for our wedding, my fiance and I, and we thought [TOWN] would be a great choice for us since we both have relatives living nearby.

We would like to ask for advice about a couple of issues. Is there a venue nearby that would be suitable for a wedding party? And do you think you could recommend us some affordable accommodation?

Thank you in advance,

Sincerely

[Sender]

\section{A.3.3 Request 3}

Dear Sir/Madam

I am planning to do a bike trip with my family around [TOWN].

We would like to ask for advice about a couple of issues. Is there a bike trail in the area? Could you recommend us affordable camping sites in the area? And is there a limit on how long we may stay?

Thank you in advance,

Sincerely

[Sender]

\section{A.3.4 Request 4}

\section{Dear Sir/Madam}

Our family is thinking of moving house, and we would like to ask you for some advice regrading nurseries in $[\mathrm{TOWN}]$.

We have four kids ( a 2, 9, 11 and a 12-year-old) and we are looking for daycare options for the youngest. Could you please provide information about local public daycares, and if there 
are not any, about ones in the area? We would also be grateful if you could inform us about the expected date of enrollment and about fees. And are we right in assuming that we would qualify for free school lunch as a big family?

Thank you in advance,

Sincerely

[Sender]

\section{A.4 Emails addresses/names}

\begin{tabular}{lll}
\hline \hline & Roma emails & majority-emails \\
\hline Female & $\begin{array}{l}\text { lakatos.evelin1988@gmail.com } \\
\text { orsos.dzsenifer88@gmail.com }\end{array}$ & $\begin{array}{l}\text { bernadett.toth1986@gmail.com } \\
\text { molnar.panna84@gmail.com } \\
\text { molnarpanna85@gmail.com }\end{array}$ \\
\multirow{2}{*}{ Male } & $\begin{array}{l}\text { kanalas.kevin86@gmail.com } \\
\text { kolompar.mario84@gmail.com }\end{array}$ & $\begin{array}{l}\text { matenagy1983@gmail.com } \\
\text { petervarga0086@gmail.com }\end{array}$ \\
\hline \hline
\end{tabular}




\section{B Coding rules for response quality}

\section{B.1 General considerations}

The holistic logic of the coding was to disentangle the factual content of the response letters from the manner and tone in which they were written. This is not an easy task: politeness often correlates with the degree to which responses contain information. However, we took this principle very seriously.

\section{B.2 Coding helpfulness}

We first placed response emails into 4 groups, as described below:

- 0 point: None of the inquiries is answered.

- 1 point: Only one of the inquiries is answered.

- 2 points: Some of the inquiries are answered/Refers to another institution to contact but no contact information provided

- 3 points: All of the inquiries are answered/Refers to another institution and provides contact information

We then added an extra point if the response included further instructions on how to solve the problems raised by the inquiry, or some other creative ideas. The final scores are characterized below with examples for each provided.

3 points: The answer encompasses all of the expected content and is considered to be useful.

\section{Dear XXXX}

I would like to inform you that if you are thinking of a civil marriage ceremony, the joint presence of the groom and the bride is required at the registrar. The intent to marry needs to be recorded in writing, and during the procedure birth certificates, personal identification documents (identity card or passport), proof of marital status documents (in the case of being divorced or widowed), as well as address cards must be presented. If the two witnesses have 
already been chosen, their records (personal identification number) ID card, address card) also needs to be presented. The ceremony can take place after 32 days after submitting a letter of intent.

On weekdays - and during office hours - ceremonies can be held for free at the Mayor's office and in the Hungarian-Serbian Agricultural Trade Center. Outside these location (e.g. Márta Sántha Cultural House and Library, or other room) and outside office hours there is a fee of HUF 17,000 on the premises of the local government of $[\mathrm{X}]$.

I would like to inform you that the Hungarian-Serbian Agricultural Trade Center can only be used from about early October on. Of course, due to the coronavirus epidemic, we reserve the right to make changes during the epidemiological preparedness period. The question arises as to what exactly you mean by a wedding venue, what you mean by a venue for a civil ceremony or a wedding, or both ... the answer also depends on the number of people to be invited. I do not know of accommodations in XXXX - perhaps your relatives could ask around in XXXX or in nearby villages.

If you have any further questions or comments, please do not hesitate to contact me again.

Hope this helps,

Best regards,

XXXX

2 points: The answer contains most of the expected content and is considered to be useful.

Dear XXXX

In XXXX the Granary Center (restaurant and B \& B) is a nice venue for such a ceremony. You can have the ceremony there, in the open, if the weather permits it. There are also places to stay at, and they could also serve as venues for a party. I recommend that you check the website of the venue online. I can also recommend our own wedding room.

Hope this helps,

Best regards,

XXXX 
1 point: The answer contains little of the expected content and is considered non-useful.

\section{Dear XXXX}

As an outdoor venue the couple can use the courtyard of the government building.

Best regards,

XXXX

0 point: The answer contains none of the expected content and is considered non-useful.

\section{Dear XXXX}

Thank you for you inquiry about organizing your wedding. Unfortunately due to the Mayor's Office's scope of duties we are unable to provide a response to your question.

Best,

XXXX

\section{B.3 Coding politeness}

We defined the following essential and non-essential indicators for politeness.

Essential:

- Basic formal requirements for a letter are fulfilled. (The letter contains these elements: greeting, body, closing, signature.)

- A polite tone is used

Non-essential:

- After the greetings section the administrator thanks the requester for the inquiry

- The letter contains elements of kindliness. (for example: We wish you a pleasant vacation in our community!) 
We defined politeness in two steps. First, we evaluated whether the letter contained the essential requirements for politeness.

- 2 points: The letter contains all essential requirements for politeness.

- 1 point: The letter contains some essential requirements for politeness.

- 0 point: The letter does not contain essential requirements for politeness.

In cases where the response contained all essential requirements for politeness, we checked whether the letter contained at least one extra requirement for politeness. We added 1 point to the score when the letter contained at least one extra requirement for politeness. The final scores with examples are below.

3 points: The letter contains all the essential requirements for politeness and at least one extra requirement for politeness.

\section{Dear X}

Thank you for thinking of our town as a place for your wedding. In XX there are so many beautiful places for young couples to hold wedding ceremonies. Not only is our public park exceptional, but there are two lakes in the middle of the town, which make for perfect photo ops. There is a private beach on one of the lakes but it is open to the public after the summer season - you can walk around and take photos. The other lake is also picturesque and is also often used for photo ops. If you are not familiar with our town I would recommend that you search these places online - they are both gorgeous.

We have recently renovated our wedding room, ready to be used by couples and their guests, offering an elegant and exquisite milieu.

As for the venue for the party I would recommend Negresco Restaurant, which offers fine dining and views on the lake, or the more traditional Halászkert with mid-range prices. You can look up both online if you are interested.

I hope I was able help,

Best regards,

XXX 
2 points: The letter contains all the essential requirements for politeness.

\section{Dear XXXX}

Thank you for thinking of our town as a place for your wedding. In X I can only recommend our wedding room, which is in the attic of our cultural center. I cannot think of an outdoor location. I can only remember one or two weddings held outdoors but those were in private resorts. In a neighboring village there are multiple venues that may be suitable for holding wedding parties. But I could not recommend specific places as I don't know them well. I think they are probably advertised online, too.

I would also suggest that you look for accommodation online. Look at the website of the town or other places.

Yours truly,

XXX

1 point: The letter contains some of the essential requirements for politeness.

\section{Dear XXXX}

I would like to inform you that I can recommend the George Castle as a venue. Unfortunately there is no possibility of accommodation. That could be solved in nearby villages.

XXXX

0 point: The letter does not contain any of the essential requirements for politeness.

If you would like to marry here, you need to register. I cannot give you information about venues.

XXXX 


\section{B.4 Inter-coder reliability}

Agreement between the qualitative coding of responses was imperfect as shown in Table OA1. The low rate of agreement is likely to reflect the inherent difficulty of the task. To reduce noise in our dependent measures we use the simple average of the ratings for both outcome measures.

Table OA1: Treatment effects on response rates

\begin{tabular}{llllll}
\multicolumn{2}{l}{ Helpfulness } \\
\hline Rater 1 & \multicolumn{5}{c}{ Rater 2} \\
\hline \multicolumn{5}{c}{ Helpfulness } \\
\hline 0 & 0 & 1 & 2 & 3 & Total \\
1 & 8 & 47 & 37 & 2 & 12 \\
2 & 3 & 58 & 462 & 240 & 763 \\
3 & 1 & 1 & 48 & 360 & 410 \\
\hline Total & 18 & 109 & 548 & 612 & 1,287 \\
\hline \multicolumn{5}{c}{ Rater 2} \\
\hline Rater 1 & \multicolumn{5}{c}{} \\
\hline \multicolumn{7}{c}{1} & 2 & 3 & Total \\
\hline 0 & 2 & 2 & 1 & 0 & 5 \\
1 & 4 & 18 & 38 & 5 & 65 \\
2 & 25 & 249 & 570 & 125 & 969 \\
3 & 6 & 5 & 53 & 185 & 249 \\
\hline Total & 37 & 274 & 662 & 315 & 1,288 \\
\hline \hline
\end{tabular}

\section{Supplementary analyses}

We report our main results using the specifications declared in our PAP in Table OA2. The results are by-an-large similar, though some of the estimates on the interaction of Roma and Treatment are no-longer statistically significant. We note that standard errors in these specifications tend to be larger reflecting the problem that our declared covariates do not appear to be predictive of the outcomes.

We report our estimates of the Complier Average Cauaal effects in Table . In these specifications, we use a measure of treated status based on the mass mailing software used by HCLU and only classify units as treated if they opened the email from HCLU. Analogously, we create an interaction of these variable (Opened email) and Roma treatment. We use the randomly assigned treatment as instruments. As expected, the obtained estimates are much larger in magnitude 
Table OA2: Treatment effects on response rates

\begin{tabular}{|c|c|c|c|c|c|c|c|c|}
\hline & \multicolumn{4}{|c|}{ Wave 1} & \multicolumn{4}{|c|}{ Wave 2} \\
\hline & $(1)$ & $(2)$ & $(3)$ & (4) & $(5)$ & (6) & $(7)$ & $(8)$ \\
\hline & $\mathrm{R}$ & $\mathrm{H}$ & $H \mid R$ & $P \mid R$ & $\mathrm{R}$ & $\mathrm{H}$ & $H \mid R$ & $P \mid R$ \\
\hline \multirow[t]{2}{*}{ Roma } & $-11.5^{*}$ & $-10.4^{*}$ & $-7.5^{*}$ & $-5.7^{*}$ & $-19.3^{*}$ & $-14.8^{*}$ & $-6.6^{*}$ & $-5.8^{*}$ \\
\hline & {$[3.8]$} & {$[3.4]$} & {$[2.1]$} & {$[1.8]$} & {$[3.9]$} & {$[3.2]$} & {$[2.2]$} & {$[2.1]$} \\
\hline \multirow[t]{2}{*}{ Treated } & -3.6 & -6.6 & -0.4 & -1.0 & 0.8 & 1.3 & 1.0 & -1.2 \\
\hline & {$[3.6]$} & {$[3.5]$} & {$[2.1]$} & {$[1.8]$} & {$[3.6]$} & {$[3.2]$} & {$[1.9]$} & {$[1.8]$} \\
\hline \multirow[t]{2}{*}{ Treated X Roma } & 9.1 & 7.3 & 0.5 & 2.6 & 2.0 & 0.8 & 0.8 & 2.5 \\
\hline & {$[5.4]$} & {$[4.8]$} & {$[3.1]$} & {$[2.6]$} & {$[5.6]$} & {$[4.6]$} & {$[3.1]$} & {$[3.0]$} \\
\hline \multirow[t]{2}{*}{ Female } & 2.5 & -2.7 & $-2.6^{*}$ & -0.1 & $-8.3^{*}$ & -3.1 & 2.8 & $3.0^{*}$ \\
\hline & {$[2.6]$} & {$[2.4]$} & {$[1.5]$} & {$[1.3]$} & {$[2.7]$} & {$[2.3]$} & {$[1.5]$} & {$[1.4]$} \\
\hline \multirow[t]{2}{*}{ Cemetary } & $18.5^{*}$ & $12.1^{*}$ & -3.4 & $-7.4^{*}$ & $19.6^{*}$ & $13.5^{*}$ & 0.5 & -3.7 \\
\hline & {$[3.9]$} & {$[3.4]$} & {$[2.3]$} & {$[1.9]$} & {$[3.9]$} & {$[3.3]$} & {$[2.1]$} & {$[2.0]$} \\
\hline \multirow[t]{2}{*}{ Nursery } & $11.5^{*}$ & 4.8 & $-4.8^{*}$ & $-6.3^{*}$ & 7.0 & -2.1 & $-8.7^{*}$ & $-7.7^{*}$ \\
\hline & {$[4.1]$} & {$[3.5]$} & {$[2.4]$} & {$[2.0]$} & {$[4.0]$} & {$[3.2]$} & {$[2.2]$} & {$[2.1]$} \\
\hline \multirow{2}{*}{ Wedding } & 7.2 & 2.3 & -0.2 & -3.2 & $13.2^{*}$ & 1.7 & 1.5 & -1.1 \\
\hline & {$[4.2]$} & {$[3.6]$} & {$[2.4]$} & {$[2.0]$} & {$[3.9]$} & {$[3.2]$} & {$[2.2]$} & {$[2.1]$} \\
\hline \multirow[t]{2}{*}{ Constant } & $66.2^{*}$ & $43.9^{*}$ & $81.3^{*}$ & $73.3^{*}$ & $71.3^{*}$ & $42.2^{*}$ & $76.4^{*}$ & $67.0^{*}$ \\
\hline & {$[3.9]$} & {$[3.5]$} & {$[8.1]$} & {$[6.7]$} & {$[3.9]$} & {$[3.2]$} & {$[7.9]$} & {$[7.7]$} \\
\hline Heckman correction & & & $\checkmark$ & $\checkmark$ & & & $\checkmark$ & $\checkmark$ \\
\hline
\end{tabular}

Notes: Estimates in (1), (2), (5) and (6) are from linear models. Estimates in (3),(4), (7) and (8) are from Heckman selection models with randomly assigned follow-up as an excluded predictor of the selection equation. Each regression includes blocked fixed effects. Robust standard errors in brackets. ${ }^{*}$ denotes statistical significance at $5 \%$.

than our estimates of intent to treat effect - though also much less precisely estimated.

Table OA3: Treatment effects accounting for non-compliance

\begin{tabular}{lllll}
\hline & \multicolumn{2}{l}{ Wave 1} & \multicolumn{2}{l}{ Wave 2} \\
\cline { 1 - 4 } DV & $\mathrm{R}$ & $\mathrm{H}$ & $\mathrm{R}$ & $\mathrm{H}$ \\
\cline { 2 - 4 } Opened email & -21.0 & $-56.1^{* *}$ & 3.9 & 9.5 \\
& {$[24.7]$} & {$[26.1]$} & {$[19.2]$} & {$[18.3]$} \\
Opened email X Roma & $55.9^{*}$ & $71.9^{* *}$ & 6.7 & -4.3 \\
& {$[32.9]$} & {$[31.8]$} & {$[30.2]$} & {$[25.5]$} \\
Roma & $-12.5^{* * *}$ & $-12.9^{* * *}$ & $-18.1^{* * *}$ & $-14.2^{* * *}$ \\
& {$[3.6]$} & {$[3.3]$} & {$[3.7]$} & {$[3.1]$} \\
Constant & $77.4^{* * *}$ & $48.6^{* * *}$ & $76.3^{* * *}$ & $43.6^{* * *}$ \\
& {$[2.5]$} & {$[2.5]$} & {$[2.3]$} & {$[2.2]$} \\
Observations & & & & \\
\hline \hline
\end{tabular}

Notes: Estimates are from 2SLS models where Opened email and Opened email X Roma are edogenous variables instrumented with Treatment and Treatment X Roma. Robust standard errors in brackets 